\title{
Uterine progesterone signaling is a target for metformin therapy in PCOS-like rats
}

\author{
Min Hu1,2,*, Yuehui Zhang1,3,*, Jiaxing Feng3,*, Xue Xu33, Jiao Zhang4, Wei Zhao3, Xiaozhu Guo3, Juan Li1,2, \\ Edvin Vestin1, Peng Cui1,5,6, Xin Lị1,7, Xiao-ke Wu33, Mats Brännström9, Linus R Shao' and Håkan Billig'
}

'Department of Physiology/Endocrinology, Institute of Neuroscience and Physiology, The Sahlgrenska Academy, University of Gothenburg, Gothenburg, Sweden

2Department of Traditional Chinese Medicine, The First Affiliated Hospital of Guangzhou Medical University, Guangzhou, China 3Department of Obstetrics and Gynecology, Key Laboratory and Unit of Infertility in Chinese Medicine, First Affiliated Hospital, Heilongjiang University of Chinese Medicine, Harbin, China

${ }^{4}$ Department of Acupuncture and Moxibustion, Second Affiliated Hospital, Heilongjiang University of Chinese Medicine, Harbin, China

${ }^{5}$ Department of Integrative Medicine and Neurobiology, State Key Lab of Medical Neurobiology, Shanghai Medical College and Institute of Acupuncture Research (WHO Collaborating Center for Traditional Medicine), Institute of Brain Science, Fudan University, Shanghai, China

${ }^{6}$ Institute of Integrative Medicine of Fudan University, Shanghai, China

'Department of Gynecology Obstetrics and Gynecology, Hospital of Fudan University, Shanghai, China

8Shanghai Key Laboratory of Female Reproductive Endocrine Related Diseases, Shanghai, China

${ }^{9}$ Department of Obstetrics and Gynecology, Sahlgrenska University Hospital, Sahlgrenska Academy, University of Gothenburg, Gothenburg, Sweden

Correspondence should be addressed to L R Shao: linus.r.shao@fysiologi.gu.se

*(M Hu, Y Zhang and J Feng contributed equally to this work)

\section{Abstract}

Impaired progesterone (P4) signaling is linked to endometrial dysfunction and infertility in women with polycystic ovary syndrome (PCOS). Here, we report for the first time that elevated expression of progesterone receptor (PGR) isoforms $A$ and $B$ parallels increased estrogen receptor (ER) expression in PCOS-like rat uteri. The aberrant PGR-targeted gene expression in PCOS-like rats before and after implantation overlaps with dysregulated expression of Fkbp52 and NcOa2, two genes that contribute to the development of uterine P4 resistance. In vivo and in vitro studies of the effects of metformin on the regulation of the uterine P4 signaling pathway under PCOS conditions showed that metformin directly inhibits the expression of PGR and ER along with the regulation of several genes that are targeted dependently or independently of PGR-mediated uterine implantation. Functionally, metformin treatment corrected the abnormal expression of cell-specific PGR and ER and some PGR-target genes in PCOS-like rats with implantation. Additionally, we documented how metformin contributes to the regulation of the PGR-associated MAPK/ERK/p38 signaling pathway in the PCOS-like rat uterus. Our data provide novel insights into how metformin therapy regulates uterine P4 signaling molecules under PCOS conditions.

\section{Key Words}

- metformin

- progesterone receptor

- MAPK/ERK/p38 signaling pathway

- implantation

- polycystic ovary syndrome

\section{Introduction}

Polycystic ovary syndrome (PCOS) is a clinically and etiologically heterogeneous hormone-imbalance disorder that is associated with multiple reproductive and metabolic abnormalities (Rosenfield \& Ehrmann
2016). Women suffering from PCOS present with arrested folliculogenesis and chronic anovulation-linked infertility (Azziz et al. 2016, Rosenfield \& Ehrmann 2016), and they also have more adverse reproductive risk as evidenced 
by an increase in the prevalence of implantation failure, recurrent miscarriage, spontaneous abortion, premature delivery, endometrial carcinoma (Goodarzi et al. 2011, Shao et al. 2014b, Palomba et al. 2015). In addition to the ovarian dysfunction (Azziz et al. 2016, Rosenfield \& Ehrmann 2016), it is assumed that the impairment of endometrial function also contributes to PCOS-associated infertility (Evans et al. 2016). Although progesterone (P4)-based oral contraceptive therapy is often efficacious (Vrbikova \& Cibula 2005, Lopes et al. 2014), perturbations in endometrial P4 signaling that result from attenuated responsiveness and resistance to $\mathrm{P} 4$ are common in the endometrium of a PCOS patient (Li et al. 2014a, Piltonen 2016). P4 resistance is a condition in which tissues and cells do not respond appropriately to $\mathrm{P} 4$ (Chrousos et al. 1986), and this is evidenced by endometriosis and endometrial hyperplasia that may progress to endometrial carcinoma despite supplementation with $\mathrm{P} 4$ or its analogs (Gunderson et al. 2012, Shao et al. 2014a). Gene profiling experiments have shown that different endometrial genes are likely to act in concert in this abnormal condition in PCOS patients (Kim et al. 2009, Savaris et al. 2011); however, how changes in the expression of P4 signaling molecules contribute to the P4 resistance in a PCOS patient's endometrium is poorly understood.

$\mathrm{P} 4$ is an essential contributing factor in female reproductive tissues that regulates multiple physiological processes such as the menstrual cycle, implantation, pregnancy maintenance and labor initiation (Evans et al. 2016). There are two major progesterone receptor (PGR) isoforms, PGRA and PGRB, both of which are involved in a common P4 signaling pathway for uterine cellspecific proliferation and differentiation (Li et al. 2014a, Patel et al. 2015). P4 binding activates both PGR isoforms and leads to translocation from the cytosol to the nucleus followed by binding to the P4-responsive elements of the target genes, resulting in alterations of PGR-targeted gene expression depending on the recruitment of co-regulators (Patel et al. 2015). It has been reported that endometrial PGR expression is elevated in PCOS patients who have anovulation compared to PCOS patients who still ovulate and to non-PCOS patients (Quezada et al. 2006, Margarit et al. 2010). Additionally, PGR activity is also modulated by the cytoplasmic mitogen-activated protein kinase (MAPK)/extracellular signal-regulated kinase (ERK) signaling pathway (Gellersen \& Brosens 2014, Patel et al. 2015). While high levels of ERK1/2 expression and activation reflect the P4-PGR signalinginduced decidualization status in human and rodent uteri (Thienel et al. 2002, Lee et al. 2013, Tapia-Pizarro et al.
2017), it remains to be determined whether suppression of MAPK/ERK signaling occurs in the endometrium and whether such dysregulation can negatively impact uterine function under PCOS conditions.

Metformin is an anti-diabetic drug that is a clinically approved treatment in PCOS patients worldwide (Naderpoor et al. 2015). Several diverse molecular mechanisms of metformin have been demonstrated in human endometrial carcinoma tissues in vivo and in different endometrial cancer cells in vitro (Shao et al. 2014b), and metformin's therapeutic effects on endometrial function are evidenced by improvement of endometrial receptivity, enhancement of endometrial vascularity and blood flow and reversion of endometrial hyperplasia and carcinoma into normal endometria in some women with PCOS (Jakubowicz et al. 2001, Palomba et al. 2006, Li et al. 2014b). Our recent studies using a PCOS-like rat model found that chronic treatment with metformin has significant antiandrogenic and anti-inflammatory impacts in the uterus (Zhang et al. 2017). Given the central role of $\mathrm{P} 4$ signaling in uterine implantation (Patel et al. 2015, Evans et al. 2016) and the ability of metformin to rescue implantation failure in some PCOS-like rats by modulating the expression of multiple implantation-related genes in the uterus in vivo (Zhang et al. 2017), we speculated that the beneficial effects of metformin might be mechanistically linked to the uterine P4 signaling pathway under pathological conditions such as PCOS. To address this hypothesis, we analyzed PCOSassociated PGR isoform expression and the MAPK signaling network in human and rat uterine tissues. By combining a PCOS-like rat model (Zhang et al. 2016) and in vitro tissue culture approach (Li et al. 2015), we aimed to determine whether metformin directly reverses aberrant PGR-targeted and implantation-related gene expression in the PCOS-like rat uterus.

\section{Materials and methods}

\section{Study approval}

All animal experiments were performed according to the National Institutes of Health guidelines on the care and use of animals and were approved and authorized by the Animal Care and Use Committee of the Heilongjiang University of Chinese Medicine, China (HUCM 2015-0112).

\section{Experimental animals and tissue preparations}

Adult female Sprague-Dawley rats $(n=134)$ were obtained from the Laboratory Animal Centre of Harbin Medical University, 
Harbin, China (License number SCXK 2013-001). Animals were housed in the animal care facility with free access to food and water and a controlled temperature of $22^{\circ} \mathrm{C} \pm 2^{\circ} \mathrm{C}$ with a $12 \mathrm{~h}$ light/darkness cycle. Estrous cycles were monitored daily by vaginal lavage according to a standard protocol (Feng et al. 2010). All rats (70 days old) with the different stages of estrous cycle used in this study were confirmed by examination of vaginal smears under a light microscope for two sequential cycles (about 8-10 days). Any PCOS-like (insulin+hCGtreated) rats that exhibited prolonged estrous cycles (more than 5 days) were excluded from the study.

Experiment 1: Rats were randomly divided into control (saline treatment, $n=20$ ) and experimental (PCOSlike, $n=20)$ groups. The experimental group was treated with insulin plus hCG to induce a PCOS-like metabolic and reproductive phenotype, and the control rats were treated with an equal volume of saline (Zhang et al. 2016, 2018). In brief, insulin was started at $0.5 \mathrm{IU} /$ day and gradually increased to $6.0 \mathrm{IU} /$ day between day 1 and the day 22 to induce hyperinsulinemia and insulin resistance, and 3.0 IU/day hCG was given on all 22 days to induce hyperandrogenism. Animals were treated with twice-daily subcutaneous injections until the end of the experiment. Rats with repeated insulin injections have not shown any hypoglycemic episodes (Poretsky et al. 1992, Bogovich et al. 1999, Damario et al. 2000, Zhang et al. 2018). Detailed analysis of endocrine and metabolic parameters as well as the uterine morphology in these animals has been reported previously (Zhang et al. 2016). On day 23, each group of rats was divided into two subgroups of 10 rats each (Supplementary Fig. 1A, see section on supplementary data given at the end of this article). For treatment, metformin was dissolved in saline and given as a daily oral dose of $500 \mathrm{mg} / \mathrm{kg}$ by a cannula. The treatment time and tissue collection are described in our previous study (Zhang et al. 2017).

Experiment 2: Rats were randomly divided into control (saline treatment, $n=21$ ) and experimental (PCOS-like, $n=15$ ) groups and treated as described in Experiment 1 (Supplementary Fig. 1B). After metformin treatment, control and PCOS-like rats were mated with fertile males of the same strain to induce implantation, which was determined by the presence of a vaginal plug (day 1 of pregnancy). The rats were killed between 08:00 and 09:00 h on day 6 of pregnancy. To identify the implantation sites, rats were injected intravenously with a Chicago Blue B dye solution (1\% in saline) and killed $10 \mathrm{~min}$ later. Uteri were dissected and assessed for clearly delineated blue bands as evidence of early implantation sites as described previously (Zhang et al. 2017).

$$
\text { http://joe.endocrinology-journals.org }
$$

Experiment 3: Rats were divided into control (saline treatment, $n=9$ ) and experimental (PCOS-like, $n=39$ ) groups and treated as described in the Experiment 1. On the 23rd day, the PCOS-like rats were divided into four subgroups and treated daily with $\mathrm{P} 4(4 \mathrm{mg} / \mathrm{kg}), \mathrm{RU} 486$ $(6 \mathrm{mg} / \mathrm{kg})$, or both for 3 days. For treatment, P4 and RU486 were dissolved in 100\% ethanol and resuspended in sesame oil. All subcutaneous injections were in a volume of $100 \mu \mathrm{L}$. An equal volume of $100 \%$ ethanol and sesame oil was injected into both healthy control rats and PCOS-like rats as experimental controls (Supplementary Fig. 1C). The pharmacological doses and treatment time intervals of P4 and RU486 were chosen on the basis of previous studies (Knox et al. 1996, Kim et al. 2006).

After dissection, the uterine horns were trimmed free of fat and connective tissue. One side of the uterus in each animal was fixed in $10 \%$ neutral formalin solution for $24 \mathrm{~h}$ at $4^{\circ} \mathrm{C}$ and embedded in paraffin for histochemical analysis. The other side was immediately frozen in liquid nitrogen and stored at $-70^{\circ} \mathrm{C}$ for Western blot and quantitative real-time PCR (qRT-PCR) analysis.

Detailed description of the methods including the primary in vitro tissue culture and treatment, morphological assessment and immunostaining, protein isolation and Western blot analysis, RNA extraction and qRT-PCR analysis, and measurement of biochemical parameters used in this study are provided in Supplementary files.

\section{Statistical analysis}

GraphPad Prism was used for statistical analysis and graphing. For all experiments, $n$-values represent the number of individual animals. Data are represented as the means \pm S.E.M. Statistical analyses were performed using SPSS, version 24.0 statistical software for Windows (SPSS). The normal distribution of the data was tested with the Shapiro-Wilk test. Differences between groups were analyzed by one-way ANOVA or two-way ANOVA, and this was followed by Tukey's post hoc test for normally distributed data or the Kruskal-Wallis test followed by the Mann-Whitney $U$ test for skewed data. All $P$ values less than 0.05 were considered statistically significant.

\section{Results}

\section{Metformin alters PGR isoform and PGR-targeted} gene expression in PCOS-like rats

The insulin +hCG-treated rats exhibit reproductive disturbances that mimic human PCOS (Zhang et al. 
2016, 2017). Prompted by these findings, we set out to investigate the impact of P4 signaling in this model. First, we showed that although the ratio of PGRA to PGRB was not significantly different between control and PCOS-like rats, the PCOS-like rats had increased levels of uterine PGRA and PGRB (Fig. 1A). While PGR immunoreactivity was primarily evidenced in control rat uterine luminal and glandular epithelia as well as in the stroma, the immunoreactivity of luminal epithelial PGR expression was associated with increased numbers of luminal epithelial cells and increased immunoreactivity of PGR in the stroma in PCOS-like rats (Fig. 1B). Metformin treatment did not significantly affect PGR isoform expression in control rats and PCOS-like rats compared to those rats treated with saline (Fig. 1A). However, we found that PGR immunoreactivity was decreased in the luminal and glandular epithelia by metformin treatment in both control rats and PCOS-like rats compared to those treated with saline (Fig. 1B). Conversely, intense immunoreactivity of PGR expression was detected in the stroma located close to the luminal epithelia in control and PCOS-like rats treated with metformin (Fig. 1B). In contrast to the epithelia and stroma, no significant changes in PGR expression in the myometrium were found in any of the groups (data not shown). Because a large body of evidence indicates that regulation of $\mathrm{P} 4$ signaling results in changes in the expression of several PGR-targeted genes in the uterus (Bhurke et al. 2016), we profiled the expression of genes that are indicators for PGR activity in the rat uterus by qRT-PCR. Quantitative data indicated that Smo, and Nr2f2 mRNA levels were increased in PCOS-like rats compared to control rats treated with saline. In contrast,

A
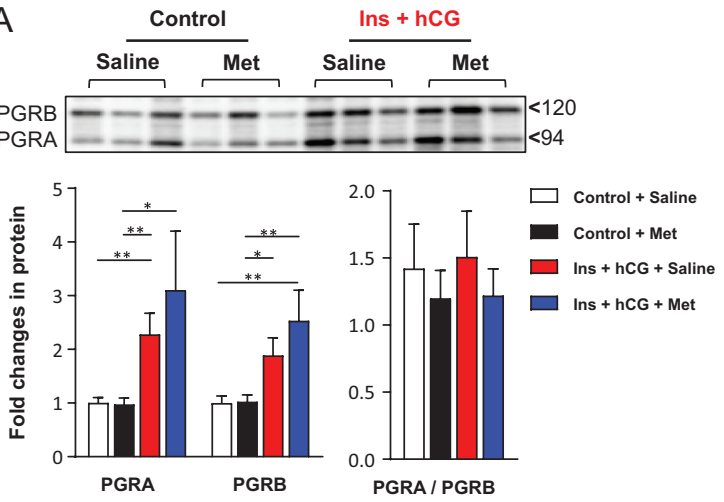

B PGRA/B

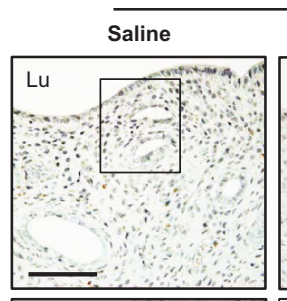

Control

Met

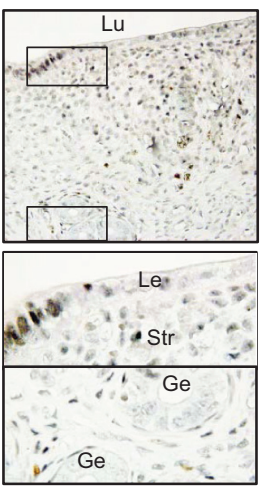

Ins + hCG

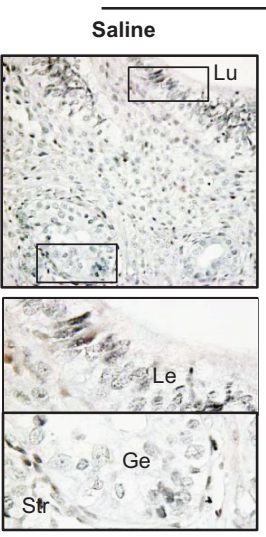

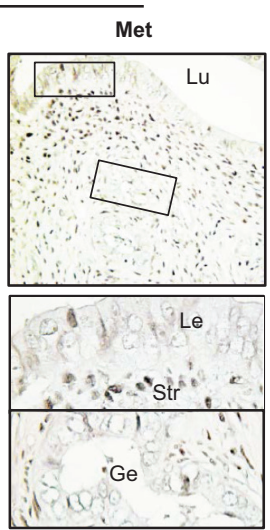

C

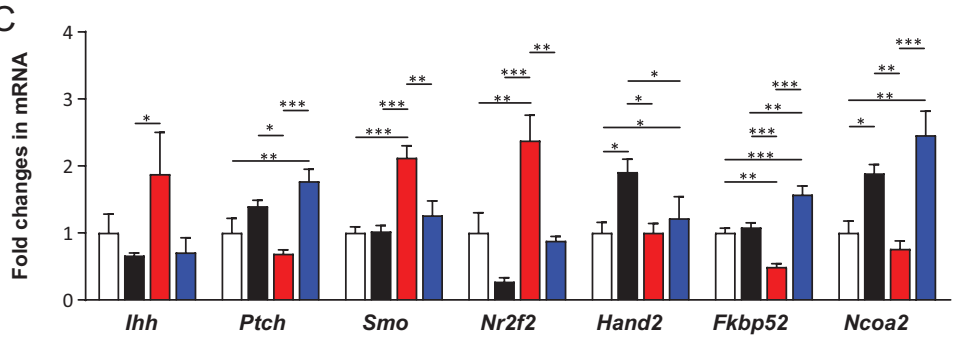

Figure 1

Chronic treatment with metformin alters PGR isoform protein expression and PGR-target gene expression in the rat uterus in vivo. (A) Western blot analysis of protein expression in the rat uterus was performed. Representative images and quantification of the densitometric data ( $n=8-9$ /group) of PGR isoforms are shown. (B) Immunohistochemical detection of PGRA/B in control rats treated with saline or metformin and in insulin + hCG-treated rats treated with saline or metformin. Representative images ( $n=5 /$ group) are shown. Lu, lumen; Le, luminal epithelial cells; $\mathrm{Ge}$, glandular epithelial cells; Str, stromal cells. Scale bars $(100 \mu \mathrm{m})$ are indicated in the photomicrographs. High magnification images are shown in the bottom panels. (C) Uterine tissues from control rats treated with vehicle or metformin and insulin + hCG-treated rats treated with saline or metformin ( $n=6 /$ group) were analyzed for mRNA levels of Ihh, Ptch, Smo, Nr2f2, Hand2, Fkbp52 and Ncoa2 by qRT-PCR. The mRNA level of each gene relative to the mean of the sum of the Gapdh and U87 mRNA levels in the same sample is shown. Values are expressed as means \pm S.E.M. Statistical tests are described in the 'Materials and methods' section. ${ }^{*} P<0.05$; $* * P<0.01 ; * * * P<0.001$. 
the Fkbp52 mRNA level was decreased in PCOS-like rats compared to control rats (Fig. 1C). We next determined the actions of metformin treatment on PGR-targeted gene expression and showed that Ptch, Fkbp52 and Ncoa2 levels were increased in PCOS-like rats treated with metformin compared to PCOS-like rats treated with saline, while Smo and Nr2f2 mRNA levels were decreased on PCOS-like rats treated with metformin compared to those treated with saline (Fig. 1C).

\section{Metformin partially prevents implantation failure in parallel with regulation of PGR isoform and PGR-targeted gene expression in PCOS-like rats}

Metformin has been shown to partially rescue the disruption of the implantation process in PCOS-like rats (Zhang et al. 2017), and the altered endocrine and metabolic parameters in these animals are shown in Supplementary Table 4. After metformin treatment, total testosterone levels, the ratio of total testosterone to androstenedione and fasting insulin levels were all significantly higher in PCOS-like rats where implantation did not occur compared to those with implantation, as was insulin resistance as assessed by the homeostasis model assessment of insulin resistance, mirroring the endocrine and metabolic abnormalities in PCOS patients (Azziz et al. 2016, Rosenfield \& Ehrmann 2016). Of note, PCOS-like rats that failed to implant embryos also exhibited decreased P4 levels. These data suggest that implantation failure in PCOS-like rats treated with metformin is due not only to hyperandrogenism and insulin resistance, but also to impairment of P4 signaling in the uterus. Further morphological characterization of metformin-treated PCOS-like rats with no implantation revealed the infiltration of immune cells into the glandular epithelial cell layer in a similar manner to when hormone imbalances were studied in a previous report (Wira et al. 2005) (Supplementary Fig. 3, black arrowheads). To determine how impairment of P4 signaling causes implantation failure, we subsequently analyzed PGR isoform and PGR-targeted gene expression in PCOSlike rats with no implantation. Although treatment with metformin increased PGR isoform expression in control and PCOS-like rats, neither the PGRA nor PGRB protein level was altered between PCOS-like rats with implantation and with failed implantation (Fig. 2A). As shown in Fig. 2B, while PGR protein was expressed in the decidualizing stroma at the site of implantation in all groups, PGR immunoreactivity was increased in the stroma of the inter-implantation region in control rats treated with metformin. Furthermore, we found that the immunoreactivity of PGR was increased in the epithelia in PCOS-like rats without implantation despite metformin treatment. Thus, metformin appeared to participate in the regulation of uterine PGR expression in a cell type-specific manner in PCOS-like rats before and after implantation. qRT-PCR data indicated that Ihh and Ncoa2 mRNAs were increased and that Ptch and Fkbp52 mRNAs were decreased in metformin-treated PCOS-like rats with no implantation compared to control rats treated with saline or metformin and to metformin-treated PCOS-like rats with implantation (Fig. 2C).

Metformin directly regulates PGR isoform, PGR-target and implantation-related gene expression in vitro

Based on these in vivo observations, we asked whether the effect of metformin was direct or indirect in the PCOSlike rat uterus. In vitro uterine tissue culture experiments revealed that Pgr and Pgrb, mRNA levels were higher in PCOS-like rats compared to control rats, in agreement with alteration of PGR isoform protein expression (Fig. 1C). Furthermore, metformin treatment increased Pgr and Pgrb mRNA levels in control and PCOS-like rats in a time-dependent manner (Fig. 3A). Consistent with the in vivo effects of metformin in PCOS-like rats (Fig. 1C), Ihh, Smo and Nr2f2 mRNA levels were increased in the PCOS-like rat uterus compared to the control rat uterus and were downregulated by metformin treatment in vitro. While the Hand $2 \mathrm{mRNA}$ level was upregulated by metformin treatment at $48 \mathrm{~h}$ and $72 \mathrm{~h}$, we detected the upregulation of Ptch, Fkbp52 and Ncoa2 mRNA levels in the PCOS-like rat uterine tissues over a 72 -h course after metformin treatment (Fig. 3A).

The expression of a number of implantation-related genes has been reported to be regulated by metformin treatment in PCOS-like rats during implantation (Zhang et al. 2017). These previous observations prompted further analysis of implantation-related gene expression by metformin treatment in vitro. In contrast to the different regulation patterns of Spp1, Lrh1, Sgk1 and Krt13 mRNAs under in vivo and in vitro conditions, the in vitro responses of uterine Prl, Igfbp1, Il11, Pc6, Maoa, Ednrb, Hoxa10, Hoxa11 and Hbegf mRNA levels to metformin (Fig. 3B) were coincident with the in vivo regulation of the expression pattern of these genes (Zhang et al. 2017). Our data indicated that metformin directly upregulates uterine Prl, Maoa, Ednrb and Hbegf mRNA levels in PCOS-like rats during implantation in vivo. 


\begin{tabular}{l|l|l|l|l|}
\hline Journal of & $\begin{array}{l}\text { M Hu, Y Zhang, J Feng } \\
\text { et al. }\end{array}$ & $\begin{array}{l}\text { Metformin and uterine } \\
\text { progesterone signaling }\end{array}$ & $\mathbf{2 3 7 : 2}$ & $\mathbf{1 2 8}$ \\
\hline Endocrinology &
\end{tabular}

A
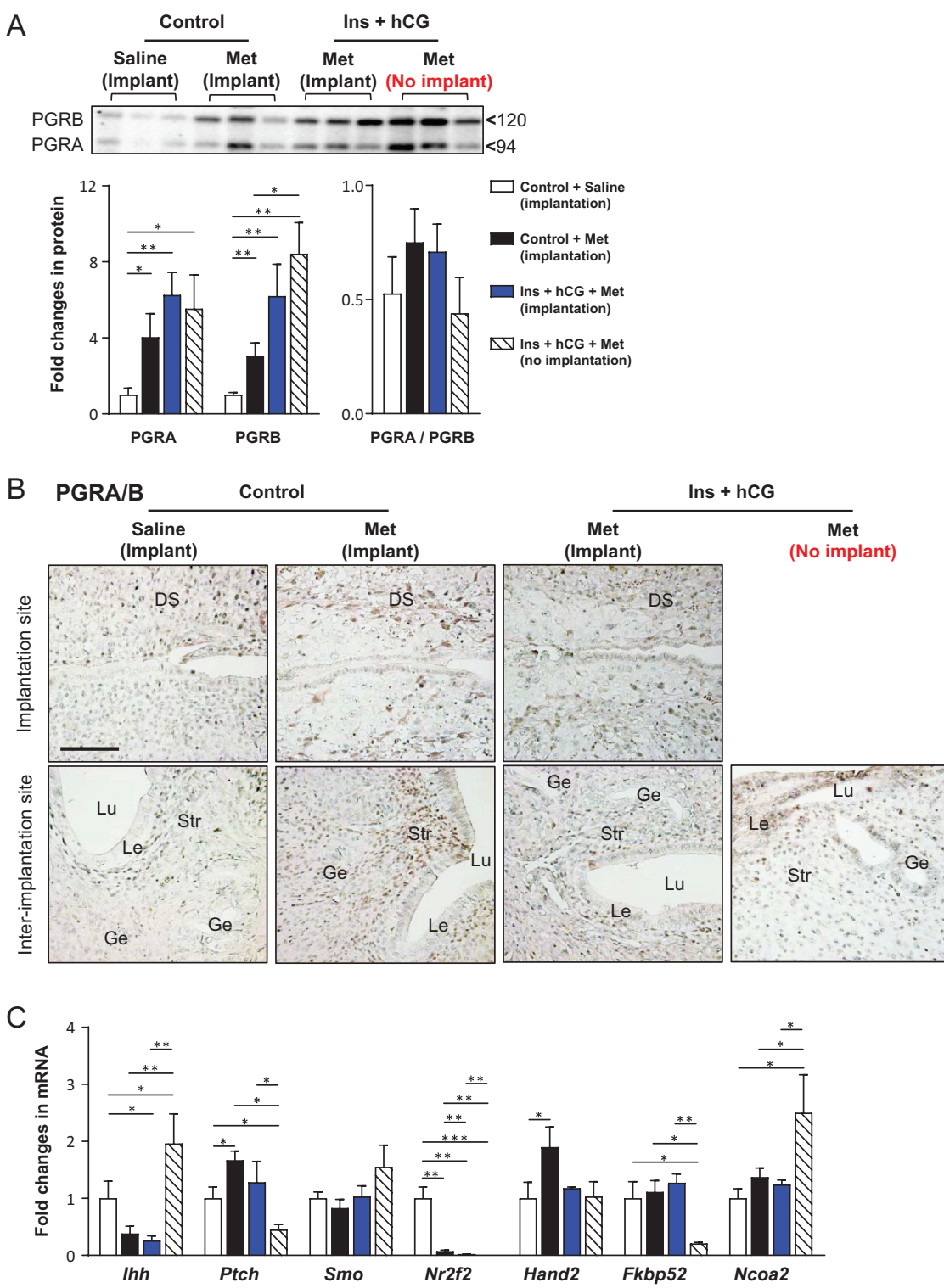

\section{Figure 2}

Chronic treatment with metformin alters PGR isoform protein expression and PGR-target gene expression in the rat uterus after implantation. (A) Western blot analysis of protein expression in the rat uterus was performed. Representative images and quantification of the densitometric data of PR isoforms are shown ( $n=5-7 /$ group). (B) Immunohistochemical detection of PGRA/B in the uterine implantation and inter-implantation sites. Representative images are shown ( $n=5 /$ group). DS, decidualized stroma; Lu, lumen; Le, luminal epithelial cells; Ge, glandular epithelial cells; Str, stromal cells. Scale bars $(100 \mu \mathrm{m})$ are indicated in the photomicrographs. (C) Uterine tissues $(n=5-6 /$ group) were analyzed for mRNA levels of Ihh, Ptch, Smo, Nr2f2, Hand2, Fkbp52 and Ncoa2 by qRT-PCR. The mRNA level of each gene is shown relative to the mean of the sum of the Gapdh and $U 87$ mRNA levels in the same sample. Values are expressed as means \pm S.E.M. Statistical tests are described in the 'Materials and methods' section. $* P<0.05 ; * * P<0.01 ; * * * P<0.001$.

To ascertain whether the modulation of uterine gene expression is P4 mediated and PGR dependent in PCOS-like rats, insulin +hCG-treated rats were injected subcutaneously with P4 and/or RU 486 for three days. As shown in Fig. 4, the increased PGR isoform protein levels (Fig. 1A) were confirmed by analysis of Pgr and Pgrb mRNA expression in the PCOS-like rat uterus. Although treatment with $\mathrm{P} 4$ and/or RU486 did not significantly affect Pgr mRNA expression, we found that Pgrb mRNA levels were decreased in PCOS-like rats compared to those rats with no treatment (Fig. 4). Among seven PGR-targeted genes (Fig. 1C), we found that Ptch, Hand2 and Fkbp52 mRNA levels were increased and that Ihh, Smo and Nr2f2 mRNA levels were decreased in PCOSlike rats treated with $\mathrm{P} 4$ compared to those rats with no Printed in Great Britain treatment. We also observed that treatment with RU486 alone or combined with $\mathrm{P} 4$ reversed the changes in Smo, Hand2 and Fkbp52 mRNA levels in PCOS-like rats (Fig. 4). No significant differences of uterine Ncoa2 mRNA expression were observed in PCOS-like rats regarding the different treatments. Based on our current experimental approaches, it is likely that another regulatory mechanism contributes to the metformin-induced upregulation of Ncoa2 mRNA levels in PCOS-like rats.

\section{Metformin regulates the MAPK signaling pathway in PCOS-like rats before and after implantation}

In an attempt to understand the changes in PGR activation and function observed in PCOS patients 


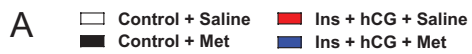
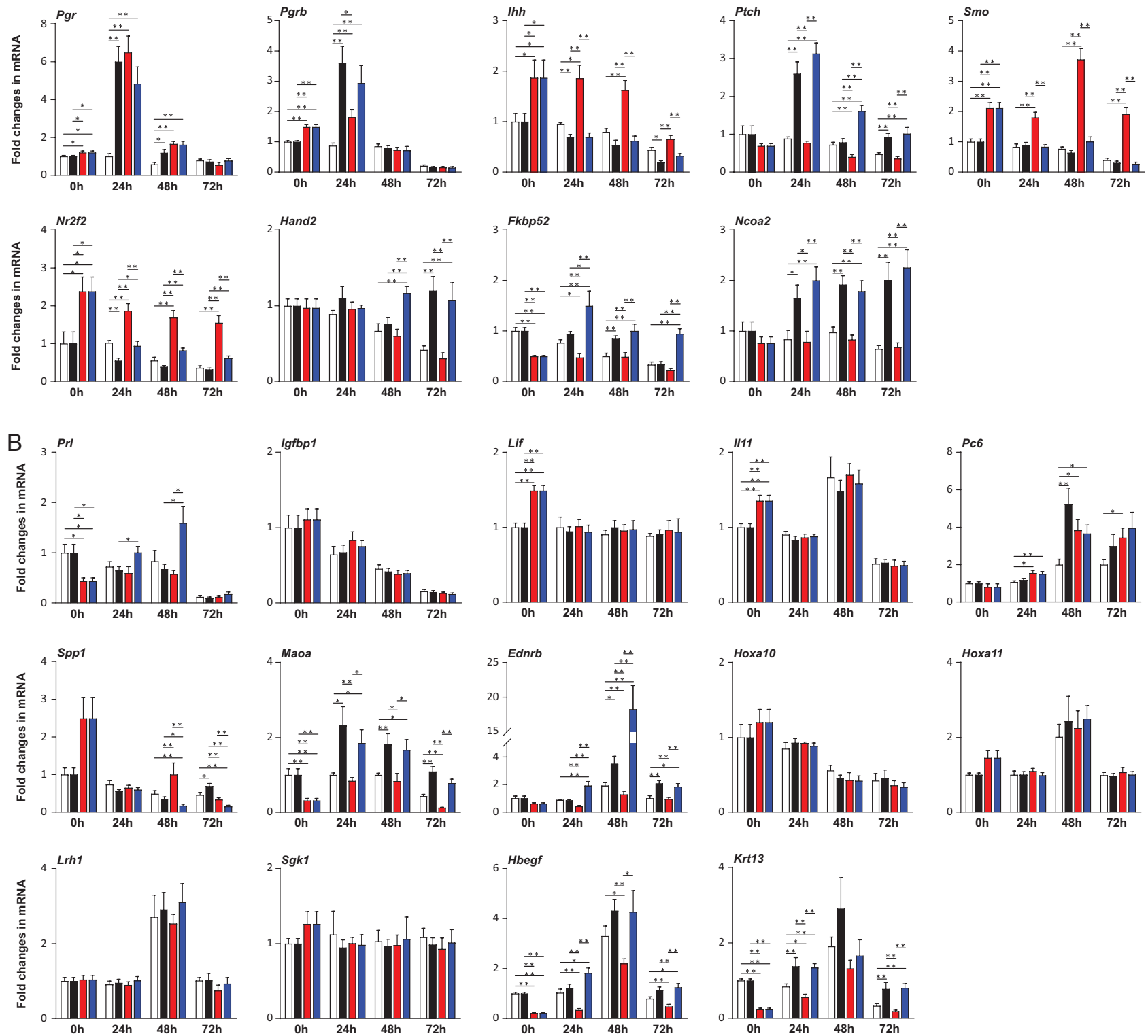

Figure 3

Specific regulation of uterine PGR isoforms, PGR-targeted and implantation-related gene expression by metformin treatment in vitro. Quantitative RT-PCR analysis of (A) Pgr, Pgrb, Ihh, Ptch, Smo, Nr2f2, Hand2, Fkbp52, and Ncoa2 and (B) Prl, Igfbp1, Lif, Il11, Pc6, Spp1, Maoa, Ednrb, Hoxa10, Hoxa11, Lrh1, Sgk1, Hbegf and Krt13 mRNA levels in rat uterine tissues treated with either saline or $10 \mathrm{mM}$ metformin for the indicated culture times ( $n=6 /$ group). mRNA levels were normalized to the average levels of Gapdh and U87 mRNA in the same sample. Values are expressed as means \pm s.E.M. Statistical tests are described in the 'Materials and methods' section. ${ }^{*} P<0.05 ; * * P<0.01 ; * * * P<0.001$.

(Patel et al. 2015), we performed a Western blot analysis to measure the expression of several proteins that are involved in the MAPK signaling pathway in the uterus after metformin treatment. As shown in Fig. 5A, there was no significant difference in p-c-Raf, p-MEK1/2, p-ERK1/2, p-p38 MAPK or p38 MAPK expression between salinetreated and metformin-treated rats. Quantitative protein data indicated that the expression of p-p38 MAPK and

\begin{tabular}{|lr}
\hline http://joe.endocrinology-journals.org & ○ 2018 Society for Endocrinology \\
https://doi.org/10.1530/JOE-18-0086 & Published by Bioscientifica Ltd. \\
Printed in Great Britain
\end{tabular}

p38 MAPK was significantly decreased in PCOS-like rats compared to control rats. Nevertheless, metformin treatment only reversed p-p38 MAPK protein expression in PCOS-like rats.

We next assessed whether the MAPK/ERK signaling pathway contributes to uterine implantation in control and PCOS-like rats treated with metformin. As shown in Fig. 5B, although the p-MEK1/2 level was decreased in 


\begin{tabular}{l|l|l|l|l|}
\hline Journal of & $\begin{array}{l}\text { M Hu, Y Zhang, J Feng } \\
\text { et al. }\end{array}$ & $\begin{array}{l}\text { Metformin and uterine } \\
\text { progesterone signaling }\end{array}$ & $\mathbf{2 3 7 : 2}$ & $\mathbf{1 3 0}$ \\
\hline Endocrinology &
\end{tabular}
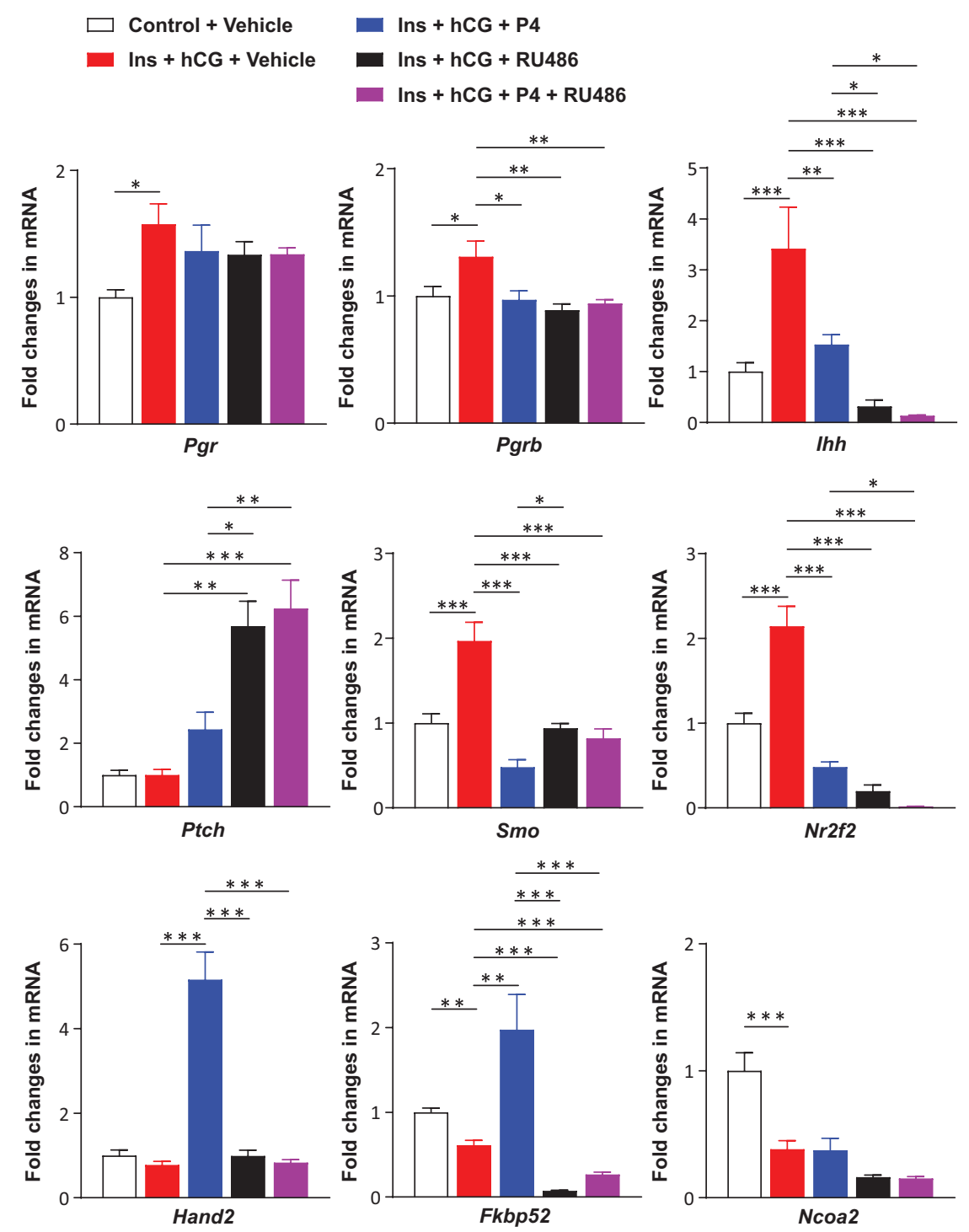

\section{Figure 4}

Specific regulation of uterine PGR isoforms and PGR-targeted gene expression by treatment with P4 and/or RU486 in vivo. Uterine tissues $(n=5-6 /$ group) were analyzed for mRNA levels of Pgr, Pgrb, Ihh, Ptch, Smo, Nr2f2, Hand2, Fkbp52 and Ncoa2 by qRT-PCR. mRNA levels were normalized to the average levels of Gapdh and U87 mRNA in the same sample. Values are expressed as means \pm s.E.m. Statistical tests are described in the 'Materials and methods' section. ${ }^{*} P<0.05$; $* * P<0.01 ; * * * P<0.001$.

control rats treated with metformin compared to control rats treated with saline, no significant difference in p-c-Raf, p-ERK1/2, ERK1/2, p-p38 MAPK or p38 MAPK expression between these two groups was found. Furthermore, our data showed that $\mathrm{p}$-c-Raf, p-MEK1/2 and p-ERK1/2 protein levels were downregulated in PCOS-like rats treated with metformin regardless of the occurrence of implantation. We also found that after metformin treatment PCOS-like rats with implantation exhibited decreased p-p38 MAPK, but not p38 MAPK, expression.

\section{Upregulation of estrogen receptor (ER) expression in PCOS-like rats can be suppressed by metformin}

Because estrogen-ER signaling regulates uterine PGR expression and activity (Li etal. 2014a, Patel etal.2015) and because increased circulating E2 in PCOS-like rats can be inhibited by metformin treatment (Zhang et al. 2017), we sought to determine whether ER subtypes (ER $\alpha$ and ER $\beta$ ) are involved in the regulation of aberrant PGR expression in PCOS-like rats and, if so, if metformin possibly alters ER subtype expression. Our data showed that PCOS-like rats exhibited increased Esr1 (ER $\alpha)$ and Esr2 (ER $\beta)$ mRNA levels, which were suppressed by metformin treatment. As shown in Fig. 6A, while nuclear ER $\alpha$ immunoreactivity was detected in the epithelia and stroma in control rats treated with saline (Fig. 6B1), immunoreactivity of ER $\alpha$ was increased in the glandular epithelia and stroma in PCOS-like rats (Fig. 6D1). Furthermore, treatment with metformin led to decreased ER $\alpha$ immunoreactivity in control (Fig. 6C1) and PCOS-like rats (Fig. 6E1). No obvious difference in ER $\alpha$ immunoreactivity was observed 


\begin{tabular}{l|l|l|l|l|} 
Journal of & $\begin{array}{l}\text { M Hu, Y Zhang, J Feng } \\
\text { et al. }\end{array}$ & $\begin{array}{l}\text { Metformin and uterine } \\
\text { progesterone signaling }\end{array}$ & $\mathbf{2 3 7 : 2}$ & $\mathbf{1 3 1}$ \\
\hline Endocrinology &
\end{tabular}

A
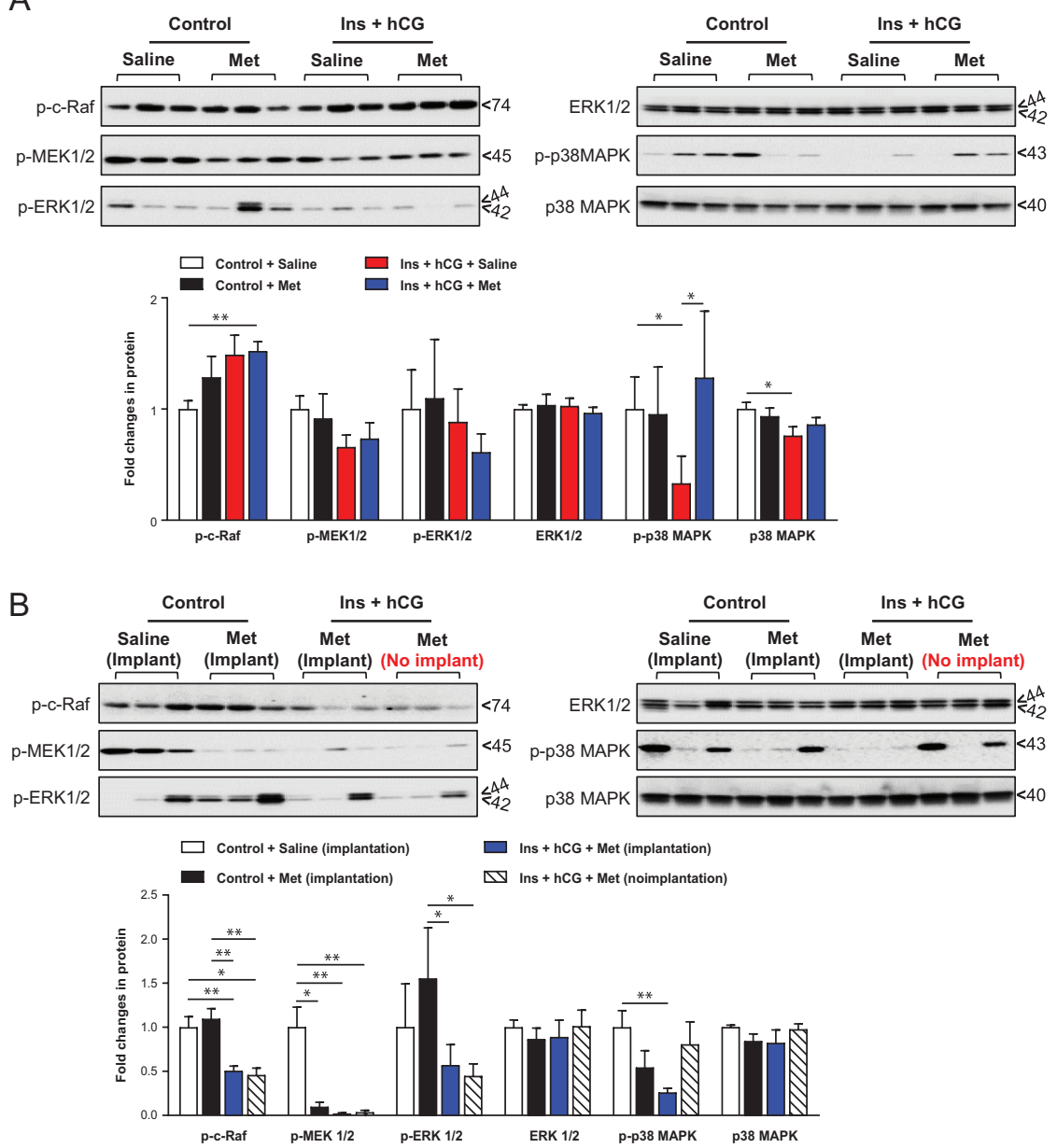

Figure 5

Chronic treatment with metformin alters the MAPK signaling pathway in the rat uterus before and after implantation. Western blot analysis of protein expression in the rat uterus was performed. Representative images and quantification of the densitometric data for p-c-Raf, p-MEK1/2, p-ERK1/2, ERK1/2, p-p38 MAPK and p38 MAPK are shown $(n=6-9 /$ group before implantation; $n=5-6 /$ group after implantation). Values are expressed as means \pm S.E.M. Statistical tests are described in the 'Materials and methods' section. ${ }^{*} P<0.05 ; * * P<0.01$ in the myometrium in any of the groups (Fig. 6B2, C2, D2 and E2). We also found that ER $\beta$ was mainly co-localized with ER $\alpha$ in the epithelia and stroma but not in the myometrium in control and PCOS-like rats regardless of the different treatments. Furthermore, with metformin treatment, we noted a significant increase in uterine Esr 1 and Esr2 mRNAs in PCOS-like rats without implantation (Fig. 7A). Immunofluorescence staining revealed that, overall, immunoreactivities of both ER $\alpha$ and ER $\beta$ were diminished in the decidualizing stroma at the site of implantation (Fig. 7B1, C1 and D1), in the epithelia and stroma of the inter-implantation region (Fig. 7B2, C2 and D2) in control rats treated with saline or metformin (Fig. 7B2 and C2), and in the inter-implantation site of PCOS-like rats treated with metformin (Fig. 7D2) compared to those rats before implantation (Fig. 6B1, C1, D1, E1, B2, C2, D2 and E2). Interestingly, PCOS-like rats with no implantation exhibited sustained nuclear ER $\alpha$ immunoreactivity in the glandular epithelia and stroma (Fig. 7E1).

\footnotetext{
http://joe.endocrinology-journals.org https://doi.org/10.1530/JOE-18-0086
}

() 2018 Society for Endocrinology Published by Bioscientifica Ltd. Printed in Great Britain

\section{Differential cell-specific expression of} phospho-histone $\mathrm{H} 3$ in PCOS-like rats treated with metformin

As previously demonstrated (Avellaira et al. 2006), p-histone $\mathrm{H3}$ is of special interest because the endometrium of PCOS patients displays high levels of p-histone $\mathrm{H} 3$, which is associated with cellular processes such as mitosis (Brenner et al. 2003). Quantitative assessment of p-histone $\mathrm{H} 3$ indicated that no significant change in p-histone $\mathrm{H} 3$ immunoreactivity was present in the epithelia or stroma in any of groups (Supplementary Fig. 4E); however, metformin treatment decreased p-histone $\mathrm{H} 3$ immunoreactivity in the myometrium in PCOS-like rats compared to those treated with saline. Of note, intensely p-histone H3-positive stromal cells close to the luminal and glandular epithelia were found in PCOS-like rats treated with metformin (Supplementary Fig. 4D2). Similarly, p-histone H3 immunoreactivity was significantly increased in the stroma at the interimplantation sites in PCOS-like rats treated with metformin 

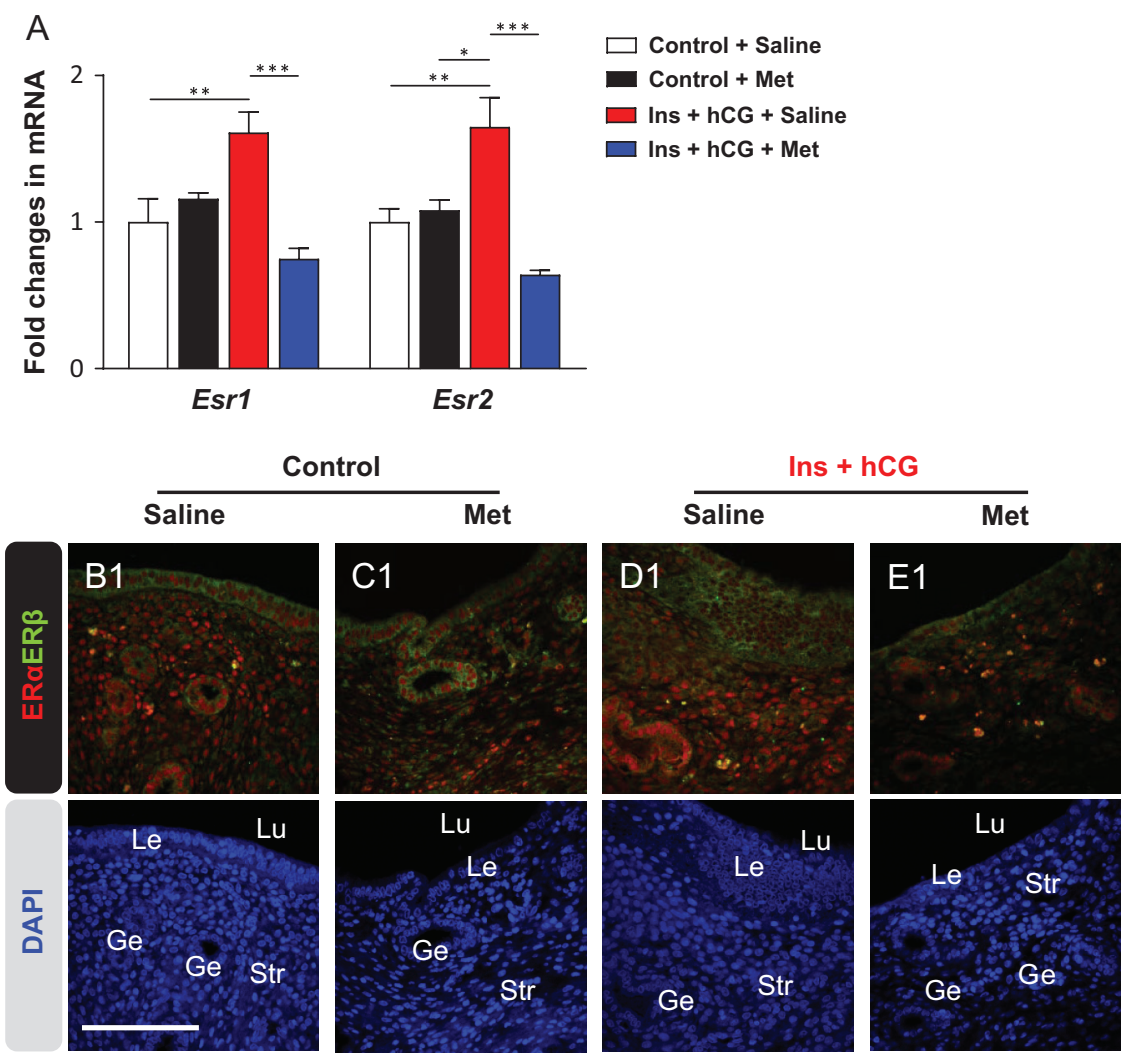

\section{Figure 6}
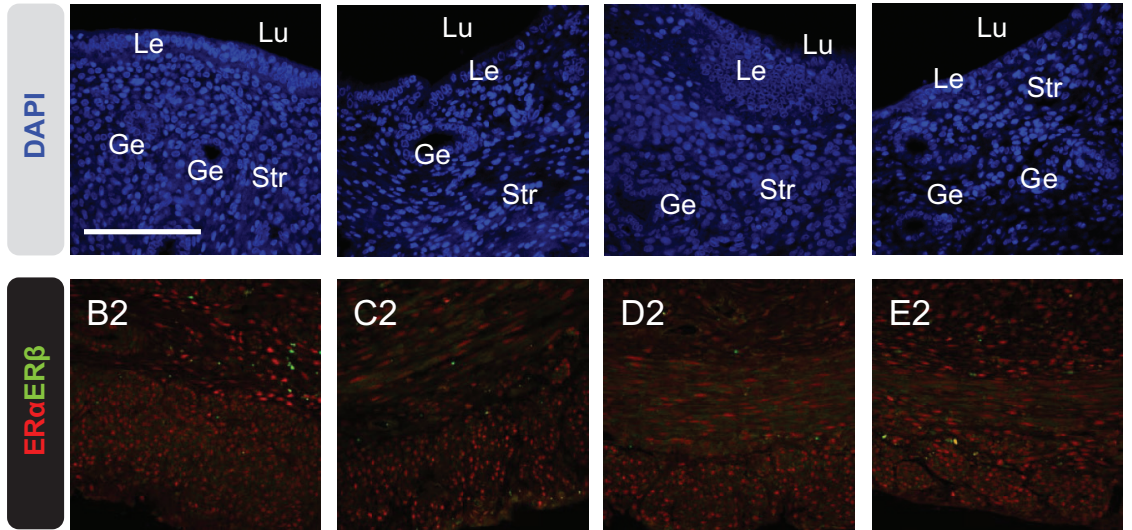

Chronic treatment with metformin alters ER subtype mRNA and protein expression in the rat uterus in vivo. (A) Uterine tissues from control rats treated with saline vehicle or metformin and insulin + hCG-treated rats treated with saline or metformin ( $n=6 /$ group) were analyzed for mRNA levels of Esr1 (ER $\alpha)$ and Esr2 (ER $\beta)$ by qRT-PCR. The mRNA level of each gene relative to the mean of the sum of the Gapdh and U87 mRNA levels in the same sample is shown. Values are expressed as means \pm S.E.M. Statistical tests are described in the 'Materials and methods' section. ${ }^{*} P<0.05 ; * * P<0.01 ; * * * P<0.001$. (B)

Immunofluorescence detection of ER $\alpha$ (red) and $\operatorname{ER} \beta$ (green) in control rats treated with saline (B1-2) or metformin (C1-2) and in insulin + hCG-
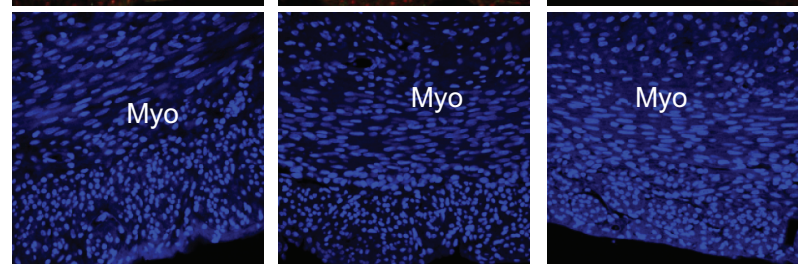

treated rats treated with saline (D1-2) or metformin (E1-2). Representative images are shown ( $n=5 /$ group). Cell nuclei were

counterstained with DAPI (blue, lower panel). Lu, lumen; Le, luminal epithelial cells; Ge, glandular epithelial cells; Str, stromal cells. Scale bars $(100 \mu \mathrm{m})$ are indicated in the photomicrographs.

independently of implantation (Supplementary Fig. 5E). In PCOS-like rats without implantation, p-histone $\mathrm{H} 3$ immunoreactivity was often detected in the luminal epithelia (Supplementary Fig. 5D1), although this was not statistically significant compared to PCOS-like rats with implantation (Supplementary Fig. 5E). It is thus likely that the regulation of mitotic activity by metformin is cell type dependent in the uterus.

\section{Discussion}

Reproductive dysfunction and infertility manifest noticeably in PCOS patients (Evans et al. 2016). In striking contrast to the attention given to hyperandrogenism and insulin resistance in women with PCOS, the aberrant P4 signaling pathway resulting in uterine $\mathrm{P} 4$ resistance has received much less attention (Li et al. 2014a, Piltonen 2016). This study is the first to show that the therapeutic effects of metformin on the regulation of uterine function in PCOS-like rats is mediated through P4 signaling.

Elucidating the regulation of endometrial PGR levels under PCOS conditions is important clinically. Our data show that increased PGR expression is paralleled with elevated ER expression in PCOS-like rats. This expression pattern is associated with an increased circulating E2 level (Zhang et al. 2016), suggests that E2-ER signaling 

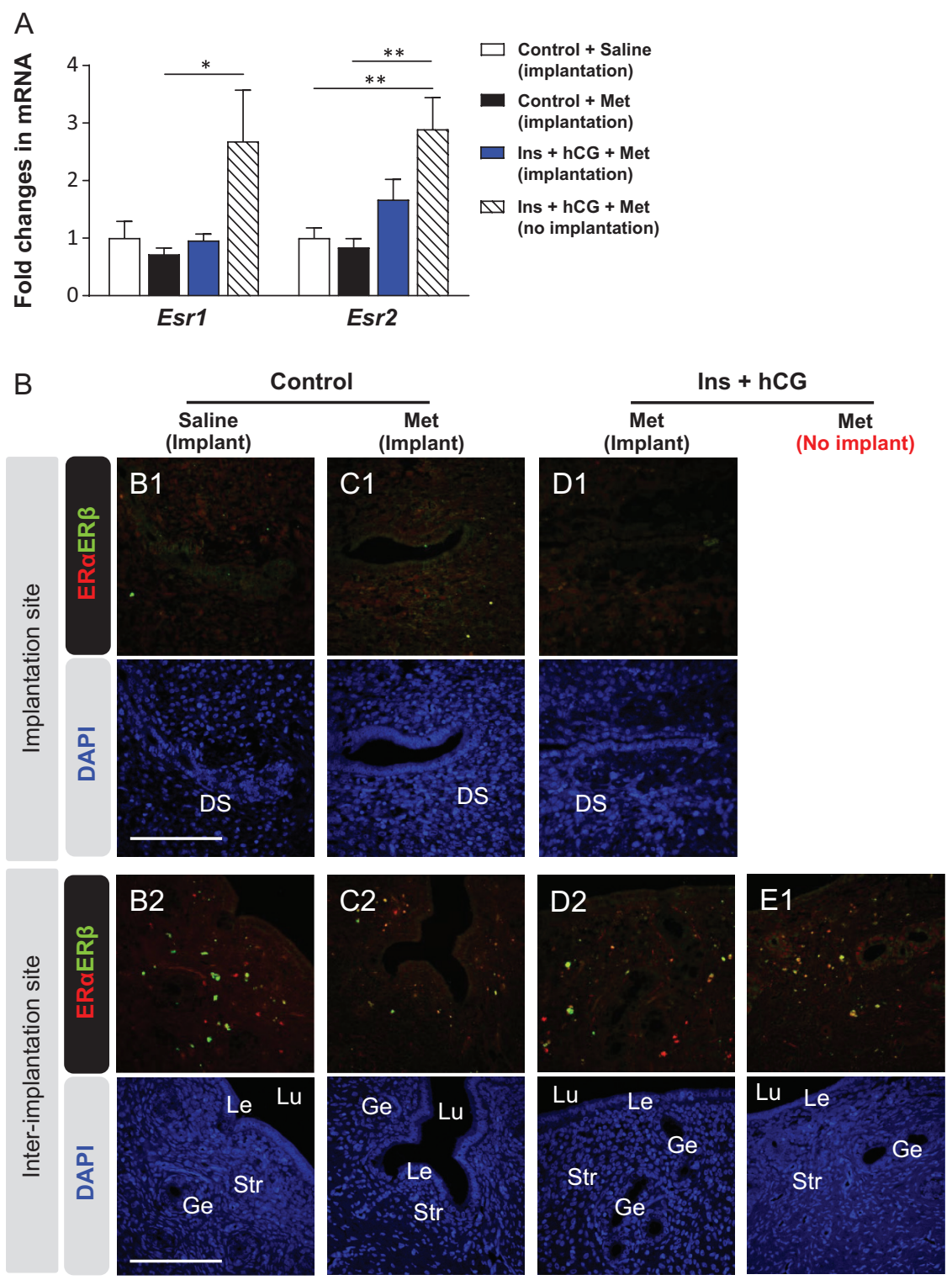

Figure 7

Chronic treatment with metformin alters ER subtype mRNA and protein expression in the rat uterus after implantation. (A) Uterine tissues from control rats treated with saline or metformin and insulin + hCG-treated rats treated with saline or metformin ( $n=5 /$ group) were analyzed for mRNA levels of Esr1 (ER $\alpha)$ and Esr2 (ER $\beta)$ by $q R T-P C R$. The mRNA level of each gene relative to the mean of the sum of the Gapdh and U87 mRNA levels in the same sample is shown. Values are expressed as means \pm s.E.M. Statistical tests are described in the 'Materials and methods' section. ${ }^{*} P<0.05 ; * * P<0.01$. (B) Immunofluorescence detection of ER $\alpha$ (red) and $\operatorname{ER} \beta$ (green) in control rats treated with saline (B1-2) or metformin (C1-2) and in insulin + hCGtreated rats treated with metformin with implantation (D1-2) or without implantation (E1). Representative images are shown $(n=5 /$ group). Cell nuclei were counterstained with DAPI (blue, lower panel). DS, decidualized stroma; Lu, lumen; Le, luminal epithelial cells; Ge, glandular epithelial cells; Str, stromal cells. Scale bars $(100 \mu \mathrm{m})$ are indicated in the photomicrographs. contributes to the upregulation of PGR under PCOS conditions in vivo. Similar to PCOS patients (M Hu et al. unpublished observations), PCOS-like rats also displayed high levels of PGR isoforms and ER subtypes in the uterus. The induction of implantation is required for the activation of PGR, and implantation subsequently alters gene expression in the endometrium (Gellersen \& Brosens 2014, Patel et al. 2015); however, PGR-targeted gene expression in PCOS patients and PCOS-like rats has only been demonstrated to a limited degree. The current study shows that significantly decreased Fkbp52 gene expression parallels increased expression of Ihh, Smo and Nr2f2 mRNAs without changes in Ncoa2 mRNA in PCOS-like rats. In addition, we also found that abnormal

$$
\begin{aligned}
& \text { http://joe.endocrinology-journals.org } \\
& \text { https://doi.org/10.1530/JOE-18-0086 }
\end{aligned}
$$

expression of PGR-target genes, including Fkbp52 and Ncoa2, is retained in PCOS-like rats with implantation failure. This is supported by in vivo studies showing that mice lacking Fkbp52 (Yang et al. 2006, Tranguch et al. 2007) or Ncoa2 (Mukherjee et al. 2006, 2007) demonstrate the absence of decidualization after P4 supplementation due to diminished P4 responsiveness. Previous studies have reported that women with endometriosis and endometrial hyperplasia/carcinoma who develop P4 resistance have low levels of PGR expression (Gunderson et al. 2012, Shao et al. 2014a). Although it is currently unclear why differences exist in the regulation of uterine PGR expression between different diseases with $\mathrm{P} 4$ resistance, it is likely that uterine $\mathrm{P} 4$ resistance 
in PCOS-like rats is due to impaired PGR activity rather than PGR expression.

Defects in PGR isoform-specific P4 signaling in the mouse uterus can give rise to distinct phenotypes of uterine impairment and implantation failure ( $\mathrm{Li}$ et al. 2014a). Here, we observed no changes in total Pgr mRNA levels but a reduction of Pgrb mRNA levels in PCOS-like rat uterus after treatment with $\mathrm{P} 4$ and/or RU486. This suggests that uterine Pgra mRNA levels are increased. Meanwhile, several PGR-target genes (e.g., Ihh, Smo, Ptch, Nr2f2, Hand2 and Fkbp52) are significantly altered in PCOS-like rats after $\mathrm{P} 4$ treatment. Thus, we speculate that changes in these P4-dependent PGR-target gene expression in PCOS-like rat uterus might be accounted for by an increase in Pgra mRNA expression. Studies of mutant mice lacking specific PGR isoform will clarify the functional differences between the two PGR isoforms in the progression of PCOS-induced uterine dysfunction.

P4-mediated and PGR-dependent regulation of ERK1/2 expression plays a critical role in humans and rodents during endometrial decidualization and implantation (Thienel et al. 2002, Lee et al. 2013, Tapia-Pizarro et al. 2017), but such regulation under PCOS conditions has not previously been reported. The inhibition of ERK1/2 expression and activation has been reported in ovarian granulosa and thecal cells in PCOS patients (NelsonDegrave et al. 2005, Lan et al. 2015), and we have previously shown that the expression and activation of uterine ERK1/2 is suppressed in rats treated with insulin and hCG to induce the PCOS phenotype (Zhang et al. 2016). The present study supports and extends this work. Here, we observed no changes in p-ERK1/2 or ERK1/2 expression in the rat uterus after prolonged treatment with insulin and hCG. However, we observed that the levels of p-c-Raf and p-MEK1/2, two upstream regulators of ERK1/2, were significantly decreased in PCOS-like rats after uterine implantation, establishing a tight link between different MAPK/ERK signaling molecules. Our data suggest that regulation of uterine ERK1/2 expression in vivo is time dependent (Thienel et al. 2002, Lee et al. 2013, TapiaPizarro et al. 2017), which is similar to the regulation of PGR isoforms and PGR-targeted gene expression. The MAPK/ERK/p38 signaling pathway contributes to the regulation of inflammation and cytokine production (Cuadrado \& Nebreda 2010, Arthur \& Ley 2013), and the dysregulation of inflammation-related molecules is associated with PCOS conditions (Matteo et al. 2010, Piltonen et al. 2013, 2015, Orostica et al. 2016). Furthermore, like the activation of $\mathrm{NFkB}$ signaling that induces the transcriptional levels of inflammation-related gene expression in ovarian granulosa cells and in serum in PCOS patients (Liu et al. 2015, Zhao et al. 2015), our previous study has shown that the sustained metformin treatment markedly suppresses uterine inflammatory gene expression,

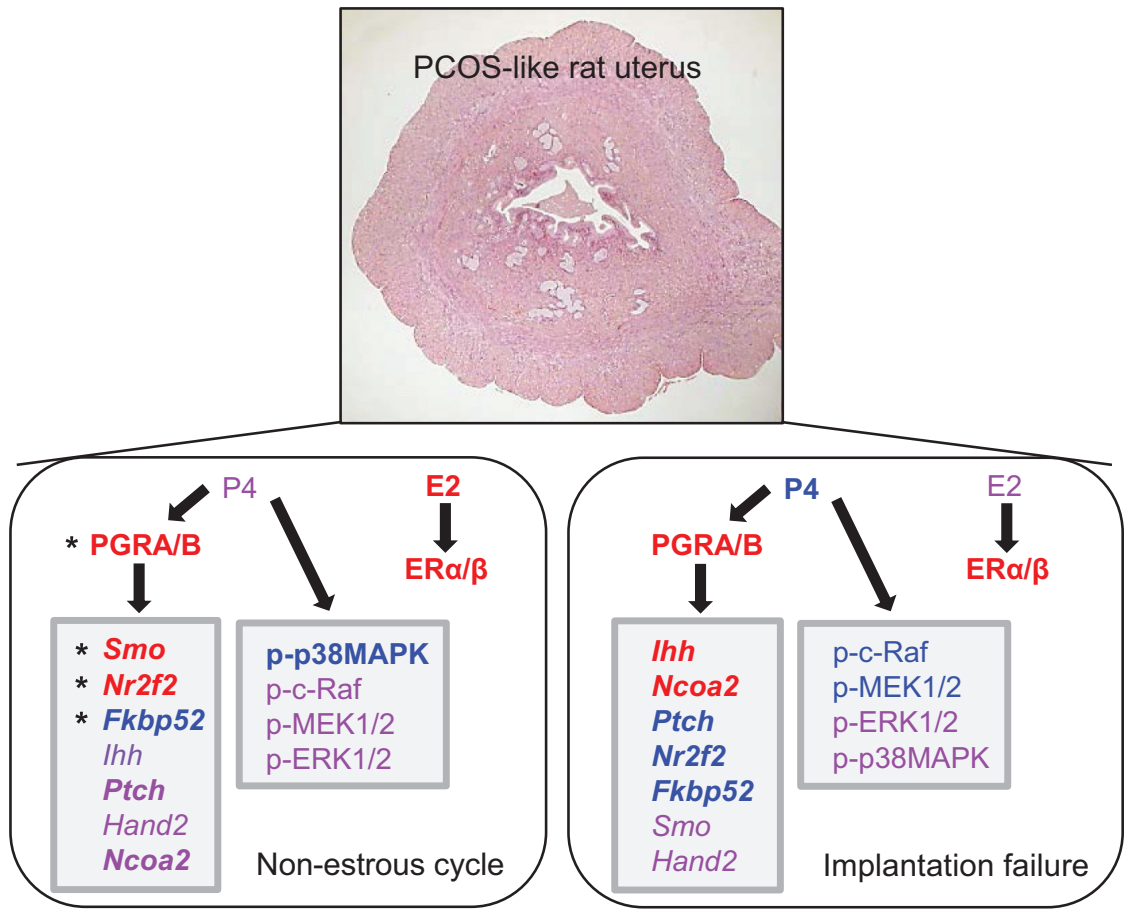

Increased expression Decreased expression Unchanged expression

\section{Figure 8}

Schematic representation of the actions of metformin on the uterine progesterone signaling in the PCOS-like rats. Note that bold symbol indicates metformin-regulated genes and proteins and asterisk indicates that treatment with metformin or progesterone shares the same targeted genes and proteins. 
especially the Il- 6 and $T N F \alpha$ mRNAs that are associated with inhibition of nuclear NFKB translocation in PCOS-like rats (Zhang et al. 2017). Importantly, p38 can antagonize ERK1/2 signaling mediated by protein phosphatase $2 \mathrm{~A}$ and consequently down-regulate inflammatory cytokine and chemokine production (Cuadrado \& Nebreda 2010), and the anti-inflammatory effects of MAPK/p38 are involved in the regulation of NFkB activity (Arthur \& Ley 2013). These observations further indicate that metformin inhibits NFkB-driven inflammatory processes through p38 activation rather than through ERK1/2 inhibition in the PCOS-like rat uterus.

The results of the present study permit us to draw the following conclusions (Fig. 8). (1) With sustained low levels of P4, the expressions of both uterine PGR isoforms are elevated in PCOS-like rats in vivo. This is positively associated with the high levels of ERs in PCOS-like rats. Consistent with mouse-knockout studies, altered expression of $F k b p 52$ and Ncoa2, two genes that contribute to uterine P4 resistance, is seen in PCOS-like rats before and after implantation. (2) Metformin directly suppresses uterine PGR isoform expression along with the correction of aberrant expression of PGR-targeted and implantation-related genes in PCOSlike rats. Abnormal cell-specific regulation of PGR and ER, paralleling the aberrant expression of PGR-targeted and implantation-related genes, is retained in PCOS-like rats with implantation failure. (3) Increased PGR expression is associated with inhibition of the MAPK/ERK/p38 signaling pathway, and the primary effect of metformin treatment is to restore the MAPK/p38 signaling pathway in the PCOSlike rat uterus. Taken together, our findings provide support for metformin therapy in the improvement of P4 signaling in PCOS-like rats with uterine dysfunction and for its clinical relevance in the treatment of PCOS patients with P4 resistance.

\section{Supplementary data}

This is linked to the online version of the paper at https://doi.org/10.1530/ JOE-18-0086.

\section{Declaration of interest}

The authors declare that there is no conflict of interest that could be perceived as prejudicing the impartiality of the research reported.

\section{Funding}

Research reported in this publication was supported by the Swedish Medical Research Council (grant number 10380), the Swedish federal government under the LUA/ALF agreement (grant number ALFGBG-147791), the Jane and Dan Olsson's Foundation, the Hjalmar Svensson Foundation and the Adlerbert Research Foundation (to H B and L R S) as well as the National Natural Science Foundation of China (grant number 81774136), the Project of Young Innovation Talents in Heilongjiang Provincial University (grant number UNPYSCT-2015121), the Project of Innovation Talents (Young Reserve Talents) in Harbin city (grant number 2015RAQYJ089), and the Project of Excellent Innovation Talents by Heilongjiang University of Chinese Medicine (to $\mathrm{Y} Z$ ).

\section{Acknowledgements}

The authors thank the Centre for Cellular Imaging at the University of Gothenburg and the National Microscopy Infrastructure (grant number VR-RFI 2016-00968) for providing assistance in microscopy.

\section{References}

Arthur JS \& Ley SC 2013 Mitogen-activated protein kinases in innate immunity. Nature Reviews Immunology 13 679-692. (https://doi. org/10.1038/nri3495)

Avellaira C, Villavicencio A, Bacallao K, Gabler F, Wells P, Romero C \& Vega M 2006 Expression of molecules associated with tissue homeostasis in secretory endometria from untreated women with polycystic ovary syndrome. Human Reproduction 21 3116-3121. (https://doi.org/10.1093/humrep/del183)

Azziz R, Carmina E, Chen Z, Dunaif A, Laven JS, Legro RS, Lizneva D, Natterson-Horowtiz B, Teede HJ \& Yildiz BO 2016 Polycystic ovary syndrome. Nature Reviews Disease Primers 2 16057. (https://doi. org/10.1038/nrdp.2016.57)

Bhurke AS, Bagchi IC \& Bagchi MK 2016 Progesterone-regulated endometrial factors controlling implantation. American Journal of Reproductive Immunology 75 237-245. (https://doi.org/10.1111/ aji.12473)

Bogovich K, Clemons J \& Poretsky L 1999 Insulin has a biphasic effect on the ability of human chorionic gonadotropin to induce ovarian cysts in the rat. Metabolism 48 995-1002. (https://doi.org/10.1016/S00260495(99)90196-8)

Brenner RM, Slayden OD, Rodgers WH, Critchley HO, Carroll R, Nie XJ \& Mah K 2003 Immunocytochemical assessment of mitotic activity with an antibody to phosphorylated histone $\mathrm{H} 3$ in the macaque and human endometrium. Human Reproduction 18 1185-1193. (https:// doi.org/10.1093/humrep/deg255)

Chrousos GP, MacLusky NJ, Brandon DD, Tomita M, Renquist DM Loriaux DL \& Lipsett MB 1986 Progesterone resistance. Advances in Experimental Medicine and Biology 196 317-328.

Cuadrado A \& Nebreda AR 2010 Mechanisms and functions of p38 MAPK signalling. Biochemical Journal 429 403-417. (https://doi.org/10.1042/ BJ20100323)

Damario MA, Bogovich K, Liu HC, Rosenwaks Z \& Poretsky L 2000 Synergistic effects of insulin-like growth factor-I and human chorionic gonadotropin in the rat ovary. Metabolism 49 314-320. (https://doi.org/10.1016/S0026-0495(00)90110-0)

Evans J, Salamonsen LA, Winship A, Menkhorst E, Nie G, Gargett CE \& Dimitriadis E 2016 Fertile ground: human endometrial programming and lessons in health and disease. Nature Reviews Endocrinology 12 654-667. (https://doi.org/10.1038/nrendo.2016.116)

Feng Y, Weijdegard B, Wang T, Egecioglu E, Fernandez-Rodriguez J, Huhtaniemi I, Stener-Victorin E, Billig H \& Shao R 2010 Spatiotemporal expression of androgen receptors in the female rat brain during the oestrous cycle and the impact of exogenous androgen administration: a comparison with gonadally intact males. 
Molecular and Cellular Endocrinology 321 161-174. (https://doi. org/10.1016/j.mce.2010.02.029)

Gellersen B \& Brosens JJ 2014 Cyclic decidualization of the human endometrium in reproductive health and failure. Endocrine Reviews $\mathbf{3 5}$ 851-905. (https://doi.org/10.1210/er.2014-1045)

Goodarzi MO, Dumesic DA, Chazenbalk G \& Azziz R 2011 Polycystic ovary syndrome: etiology, pathogenesis and diagnosis. Nature Reviews Endocrinology 7 219-231. (https://doi.org/10.1038/nrendo.2010.217)

Gunderson CC, Fader AN, Carson KA \& Bristow RE 2012 Oncologic and reproductive outcomes with progestin therapy in women with endometrial hyperplasia and grade 1 adenocarcinoma: a systematic review. Gynecologic Oncology 125 477-482. (https://doi.org/10.1016/j. ygyno.2012.01.003)

Jakubowicz DJ, Seppala M, Jakubowicz S, Rodriguez-Armas O, RivasSantiago A, Koistinen H, Koistinen R \& Nestler JE 2001 Insulin reduction with metformin increases luteal phase serum glycodelin and insulin-like growth factor-binding protein 1 concentrations and enhances uterine vascularity and blood flow in the polycystic ovary syndrome. Journal of Clinical Endocrinology and Metabolism 86 1126-1133.

Kim HJ, Lee GS, Ji YK, Choi KC \& Jeung EB 2006 Differential expression of uterine calcium transporter 1 and plasma membrane $\mathrm{Ca} 2+$ ATPase $1 \mathrm{~b}$ during rat estrous cycle. American Journal of Physiology: Endocrinology and Metabolism 291 E234-E241. (https://doi. org/10.1152/ajpendo.00434.2005)

Kim JY, Song H, Kim H, Kang HJ, Jun JH, Hong SR, Koong MK \& Kim IS 2009 Transcriptional profiling with a pathway-oriented analysis identifies dysregulated molecular phenotypes in the endometrium of patients with polycystic ovary syndrome. Journal of Clinical Endocrinology and Metabolism 94 1416-1426. (https://doi.org/10.1210/ jc.2008-1612)

Knox KL, Ringstrom SJ, Szabo M, Perlyn CA, Sutandi S \& Schwartz NB 1996 RU486 on an estrogen background blocks the rise in serum follicle-stimulating hormone induced by antiserum to inhibin or ovariectomy. Endocrinology 137 1226-1232. (https://doi.org/10.1210/ endo.137.4.8625893)

Lan CW, Chen MJ, Tai KY, Yu DC, Yang YC, Jan PS, Yang YS, Chen HF \& Ho HN 2015 Functional microarray analysis of differentially expressed genes in granulosa cells from women with polycystic ovary syndrome related to MAPK/ERK signaling. Scientific Reports 5 14994. (https://doi. org/10.1038/srep14994)

Lee CH, Kim TH, Lee JH, Oh SJ, Yoo JY, Kwon HS, Kim YI, Ferguson SD, Ahn JY, Ku BJ, et al. 2013 Extracellular signal-regulated kinase 1/2 signaling pathway is required for endometrial decidualization in mice and human. PLOS ONE 8 e75282. (https://doi.org/10.1371/journal. pone.0075282)

Li X, Feng Y, Lin JF, Billig H \& Shao R 2014a Endometrial progesterone resistance and PCOS. Journal of Biomedical Science 212 2. (https://doi. org/10.1186/1423-0127-21-2)

Li X, Guo JR, Lin JF, Feng Y, Billig H \& Shao R 2014b Combination of Diane-35 and metformin to treat early endometrial carcinoma in PCOS women with insulin resistance. Journal of Cancer 5 173-181. (https://doi.org/10.7150/jca.8009)

Li X, Cui P, Jiang HY, Guo YR, Pishdari B, Hu M, Feng Y, Billig H \& Shao R 2015 Reversing the reduced level of endometrial GLUT4 expression in polycystic ovary syndrome: a mechanistic study of metformin action. American Journal of Translational Research 7 574-586.

Liu M, Gao J, Zhang Y, Li P, Wang H, Ren X \& Li C 2015 Serum levels of TSP-1, NF-kappaB and TGF-beta1 in polycystic ovarian syndrome (PCOS) patients in northern China suggest PCOS is associated with chronic inflammation. Clinical Endocrinology 83 913-922. (https://doi. org/10.1111/cen.12951)

Lopes IM, Maganhin CC, Oliveira-Filho RM, Simoes RS, Simoes MJ, Iwata MC, Baracat EC \& Soares JM Jr 2014 Histomorphometric analysis and markers of endometrial receptivity embryonic implantation in women with polycystic ovary syndrome during the treatment with progesterone. Reproductive Sciences 21 930-938. (https://doi.org/10.1177/1933719113519169)

Margarit L, Taylor A, Roberts MH, Hopkins L, Davies C, Brenton AG, Conlan RS, Bunkheila A, Joels L, White JO, et al. 2010 MUC1 as a discriminator between endometrium from fertile and infertile patients with PCOS and endometriosis. Journal of Clinical Endocrinology and Metabolism 95 5320-5329. (https://doi. org/10.1210/jc.2010-0603)

Matteo M, Serviddio G, Massenzio F, Scillitani G, Castellana L, Picca G, Sanguedolce F, Cignarelli M, Altomare E, Bufo P, et al. 2010 Reduced percentage of natural killer cells associated with impaired cytokine network in the secretory endometrium of infertile women with polycystic ovary syndrome. Fertility and Sterility 94 2222-2227. (https://doi.org/10.1016/j.fertnstert.2010.01.049)

Mukherjee A, Soyal SM, Fernandez-Valdivia R, Gehin M, Chambon P, Demayo FJ, Lydon JP \& O'Malley BW 2006 Steroid receptor coactivator 2 is critical for progesterone-dependent uterine function and mammary morphogenesis in the mouse. Molecular and Cellular Biology 26 6571-6583. (https://doi.org/10.1128/MCB.00654-06)

Mukherjee A, Amato P, Allred DC, DeMayo FJ \& Lydon JP 2007 Steroid receptor coactivator 2 is required for female fertility and mammary morphogenesis: insights from the mouse, relevance to the human. Nuclear Receptor Signaling 5 e011.

Naderpoor N, Shorakae S, de Courten B, Misso ML, Moran LJ \& Teede HJ 2015 Metformin and lifestyle modification in polycystic ovary syndrome: systematic review and meta-analysis. Human Reproduction Update 21 560-574. (https://doi.org/10.1093/humupd/dmv025)

Nelson-Degrave VL, Wickenheisser JK, Hendricks KL, Asano T, Fujishiro M, Legro RS, Kimball SR, Strauss JF 3rd \& McAllister JM 2005 Alterations in mitogen-activated protein kinase kinase and extracellular regulated kinase signaling in theca cells contribute to excessive androgen production in polycystic ovary syndrome. Molecular Endocrinology 19 379-390. (https://doi.org/10.1210/ me.2004-0178)

Orostica L, Astorga I, Plaza-Parrochia F, Vera C, Garcia V, Carvajal R, Gabler F, Romero C \& Vega M 2016 Proinflammatory environment and role of TNF-alpha in endometrial function of obese women having polycystic ovarian syndrome. International Journal of Obesity 40 1715-1722. (https://doi.org/10.1038/ijo.2016.154)

Palomba S, Russo T, Orio F Jr, Falbo A, Manguso F, Cascella T, Tolino A, Carmina E, Colao A \& Zullo F 2006 Uterine effects of metformin administration in anovulatory women with polycystic ovary syndrome. Human Reproduction 21 457-465. (https://doi.org/10.1093/ humrep/dei351)

Palomba S, de Wilde MA, Falbo A, Koster MP, La Sala GB \& Fauser BC 2015 Pregnancy complications in women with polycystic ovary syndrome. Human Reproduction Update 21 575-592. (https://doi. org/10.1093/humupd/dmv029)

Patel B, Elguero S, Thakore S, Dahoud W, Bedaiwy M \& Mesiano S 2015 Role of nuclear progesterone receptor isoforms in uterine pathophysiology. Human Reproduction Update 21 155-173. (https:// doi.org/10.1093/humupd/dmu056)

Piltonen TT 2016 Polycystic ovary syndrome: endometrial markers. Best Practice and Research: Clinical Obstetrics and Gynaecology 37 66-79. (https://doi.org/10.1016/j.bpobgyn.2016.03.008)

Piltonen TT, Chen J, Erikson DW, Spitzer TL, Barragan F, Rabban JT, Huddleston H, Irwin JC \& Giudice LC 2013 Mesenchymal stem/ progenitors and other endometrial cell types from women with polycystic ovary syndrome (PCOS) display inflammatory and oncogenic potential. Journal of Clinical Endocrinology and Metabolism 98 3765-3775. (https://doi.org/10.1210/jc.2013-1923)

Piltonen TT, Chen JC, Khatun M, Kangasniemi M, Liakka A, Spitzer T, Tran N, Huddleston H, Irwin JC \& Giudice LC 2015 Endometrial stromal fibroblasts from women with polycystic ovary syndrome have impaired progesterone-mediated decidualization, aberrant cytokine profiles and promote enhanced immune cell migration in vitro. 
Human Reproduction 30 1203-1215. (https://doi.org/10.1093/humrep/ dev055)

Poretsky L, Clemons J \& Bogovich K 1992 Hyperinsulinemia and human chorionic gonadotropin synergistically promote the growth of ovarian follicular cysts in rats. Metabolism 41 903-910. (https://doi. org/10.1016/0026-0495(92)90175-A)

Quezada S, Avellaira C, Johnson MC, Gabler F, Fuentes A \& Vega M 2006 Evaluation of steroid receptors, coregulators, and molecules associated with uterine receptivity in secretory endometria from untreated women with polycystic ovary syndrome. Fertility and Sterility $\mathbf{8 5}$ 1017-1026. (https://doi.org/10.1016/j.fertnstert.2005.09.053)

Rosenfield RL \& Ehrmann DA 2016 The Pathogenesis of Polycystic Ovary Syndrome (PCOS): the hypothesis of PCOS as functional ovarian hyperandrogenism revisited. Endocrine Reviews 37 467-520. (https:// doi.org/10.1210/er.2015-1104)

Savaris RF, Groll JM, Young SL, DeMayo FJ, Jeong JW, Hamilton AE, Giudice LC \& Lessey BA 2011 Progesterone resistance in PCOS endometrium: a microarray analysis in clomiphene citrate-treated and artificial menstrual cycles. Journal of Clinical Endocrinology and Metabolism 96 1737-1746. (https://doi.org/10.1210/jc.2010-2600)

Shao R, Cao S, Wang X, Feng Y \& Billig H 2014a The elusive and controversial roles of estrogen and progesterone receptors in human endometriosis. American Journal of Translational Research 6 104-113.

Shao R, Li X, Feng Y, Lin JF \& Billig H 2014b Direct effects of metformin in the endometrium: a hypothetical mechanism for the treatment of women with PCOS and endometrial carcinoma. Journal of Experimental and Clinical Cancer Research 33 41. (https://doi. org/10.1186/1756-9966-33-41)

Tapia-Pizarro A, Archiles S, Argandona F, Valencia C, Zavaleta K, Cecilia Johnson M, Gonzalez-Ramos R \& Devoto L 2017 hCG activates Epac-Erk1/2 signaling regulating progesterone receptor expression and function in human endometrial stromal cells. Molecular Human Reproduction 23 393-405. (https://doi.org/10.1093/molehr/gax015)

Thienel T, Chwalisz K \& Winterhager E 2002 Expression of MAPkinases (Erk1/2) during decidualization in the rat: regulation by progesterone and nitric oxide. Molecular Human Reproduction 8 465-474. (https:// doi.org/10.1093/molehr/8.5.465)

Tranguch S, Wang H, Daikoku T, Xie H, Smith DF \& Dey SK 2007 FKBP52 deficiency-conferred uterine progesterone resistance is genetic background and pregnancy stage specific. Journal of Clinical Investigation 117 1824-1834. (https://doi.org/10.1172/JCI31622)

Vrbikova J \& Cibula D 2005 Combined oral contraceptives in the treatment of polycystic ovary syndrome. Human Reproduction Update 11 277-291. (https://doi.org/10.1093/humupd/dmi005)

Wira CR, Fahey JV, Sentman CL, Pioli PA \& Shen L 2005 Innate and adaptive immunity in female genital tract: cellular responses and interactions. Immunological Reviews 206 306-335. (https://doi. org/10.1111/j.0105-2896.2005.00287.x)

Yang Z, Wolf IM, Chen H, Periyasamy S, Chen Z, Yong W, Shi S, Zhao W, $\mathrm{Xu}$ J, Srivastava A, et al. 2006 FK506-binding protein 52 is essential to uterine reproductive physiology controlled by the progesterone receptor A isoform. Molecular Endocrinology 20 2682-2694. (https:// doi.org/10.1210/me.2006-0024)

Zhang Y, Sun X, Sun X, Meng F, Hu M, Li X, Li W, Wu XK, Brännström M, Shao R, et al. 2016 Molecular characterization of insulin resistance and glycolytic metabolism in the rat uterus. Scientific Reports 630679. (https://doi.org/10.1038/srep30679)

Zhang Y, Hu M, Meng F, Sun X, Xu H, Zhang J, Cui P, Morina N, Li X, Li W, et al. 2017 Metformin ameliorates uterine defects in a rat model of polycystic ovary syndrome. EBioMedicine 18 157-170. (https://doi. org/10.1016/j.ebiom.2017.03.023)

Zhang Y, Meng F, Sun X, Sun X, Hu M, Cui P, Vestin E, Li X, Li W, Wu XK, et al. 2018 Hyperandrogenism and insulin resistance contribute to hepatic steatosis and inflammation in female rat liver. Oncotarget [epub]. (https://doi.org/10.18632/oncotarget.24477)

Zhao Y, Zhang C, Huang Y, Yu Y, Li R, Li M, Liu N, Liu P \& Qiao J 2015 Up-regulated expression of WNT5a increases inflammation and oxidative stress via PI3K/AKT/NF-kappaB signaling in the granulosa cells of PCOS patients. Journal of Clinical Endocrinology and Metabolism 100 201-211. (https://doi.org/10.1210/jc.2014-2419)

Received in final form 9 March 2018

Accepted 13 March 2018

Accepted Preprint published online 13 March 2018 (c) 2018 Society for Endocrinology Published by Bioscientifica Ltd. Printed in Great Britain 